\title{
APLICAÇÃO DA FILTRAÇÃO DIRETA DESCENDENTE EM EFLUENTE DE ESGOTO SANITÁRIA PARA PRODUÇÃO DE ÁGUA DE REÚSO DIRETO
}

\author{
Marília Vasconcellos Agnesini ${ }^{*}$, Fernando Afonso Marrengula ${ }^{1}$, Cristina Filomena Pereira Rosa Paschoalato ${ }^{1}$ \\ ${ }^{1}$ Universidade de Ribeirão Preto, 14096-900, Ribeirão Preto, Brasil.
}

*E-mail: magnesini@unaerp.br

\section{RESUMO}

A escassez de água é um problema de âmbito mundial, deste modo, técnicas como o reuso, que visam suprir essa falta, reduzem a demanda sobre os recursos hídricos, poupando grandes volumes de água potável da utilização para fins menos nobres, além de diminuírem a carga de efluente nos rios. Nesse contexto, foi proposta a aplicação da tecnologia de filtração direta descendente (FDD) em areia, como tratamento terciário ao efluente secundário de estação de tratamento de esgoto sanitário (ETE), com vista à obtenção de água de reuso direto. Dentre as principais vantagens dessa tecnologia estão o baixo custo, a facilidade operacional e a produção de água com qualidade suficiente para aplicação de fins menos nobres. Para isso, foi realizado monitoramento do efluente de ETE, localizado em um município do interior paulista, com a finalidade de avaliar a qualidade da água e garantir a adequação da aplicação da FDD como recurso tecnológico. Foram realizados ensaios de tratamento em jar-test com uso do coagulante policloreto de alumínio (PAC), seguidos de oxidação com cloro. O resultado do monitoramento do efluente da ETE apontou baixos valores de turbidez, com pouca variação no período de estudo, apresentando qualidade adequada para aplicação da FDD. A dosagem otimizada para o coagulante PAC foi de $15 \mathrm{mg} \mathrm{L}^{-1}$. Os ensaios de FDD seguidos de oxidação com cloro forneceu água de reuso com cor aparente de 20 $\mathrm{uH}$; turbidez de $0,8 \mathrm{uT}$; $\mathrm{pH}$ de aproximadamente 7,5 e cloro residual livre de $1 \mathrm{mg} \mathrm{L}^{-1}$. Tais resultados atendem às recomendações de qualidade estabelecidas pela USEPA (2004) e NBR 13969 (ABNT, 1997). Pode-se concluir que a qualidade da água obtida pela aplicação da tecnologia de FDD, seguida de oxidação com cloro, atende à demanda de reuso urbano irrestrito para aplicações de uso menos nobre da água, tais como irrigação de jardins, lavagem de pisos e espaços públicos e armazenamento para combate de incêndio.

Palavras-chave: Reuso da água. Filtração Direta Descendente. Efluente de esgoto sanitário. Desinfecção.

\section{Introdução}

O cenário hídrico mundial é preocupante. Atualmente, existem 26 países que abrigam milhões de pessoas e aqueles se enquadram na categoria de áreas com escassez de água, devido à distribuição desigual dos recursos hídricos. Pelo menos $8 \%$ da reserva mundial de água doce está no Brasil, sendo que, desse montante, $8 \%$ encontra-se na Região da Amazônia e somente $20 \%$ encontrase distribuída nas regiões onde vivem $95 \%$ da população brasileira [1]. Ainda que possua abundante oferta de água, a população brasileira sofre com problemas de poluição excessiva dos mananciais. São vários os obstáculos para o tratamento e distribuição da água no país e, entre eles, está o crescimento populacional, que aumenta a demanda de água tratada. Nos últimos anos, surgiu um importante agravante: a escassez de chuvas, que reduz a quantidade de água em reservatórios, a recarga de aquíferos e o nível dos rios.

Em razão da crescente e iminente limitação da disponibilidade de água, o reuso de água ganha destaque no gerenciamento hídrico. Essa estratégia sobre a água, bem essencial à sobrevivência, leva ao atendimento da demanda de consumo racional e sustentável, a fim de que seja preservada a disponibilidade de água para presentes e futuras gerações, de que haja o controle de perdas e desperdícios e, por fim, a minimização da produção de efluentes e do consumo de água.

A prática de reuso de esgotos tratados tem um papel fundamental no planejamento e na gestão sustentável dos recursos hídricos. É uma excelente alternativa para fins agrícolas, industriais, urbanos e ambientais, além de economizar as fontes de água de boa qualidade destinada ao abastecimento público e a outros usos prioritários. Essa prática, que se tem discutido muito no Brasil, já é utilizada há algum tempo em alguns países, tendo como base o conceito de substituição de mananciais. Tal substituição é possível em razão da qualidade da água requerida para um uso específico [2]. Podem-se poupar grandes volumes de água potável através do reuso de água de qualidade inferior (geralmente efluentes pós-tratados), para atendimento das finalidades que podem prescindir desse recurso dentro dos padrões de potabilidade.

$\mathrm{O}$ reuso da água já configura uma realidade adotada no Brasil e no exterior, como prática alternativa ao gerenciamento 
hídrico, por reduzir a demanda sobre os mananciais, conforme exposto acima.

Em algumas estações de tratamento de esgotos (ETE), o procedimento da produção de água de reuso ocorre através da desinfecção com cloro em uma parcela do efluente, ocorrendo a indesejável formação de subprodutos da desinfecção, dentre eles os trialometanos, substâncias reconhecidamente cancerígenas, que se formam quando se submete água com presença de matéria orgânica ao contato com cloro, conforme Marrengula [3].

Através do monitoramento das características físicoquímicas do efluente de uma ETE, foi proposta a aplicação da tecnologia de filtração direta descendente (FDD) como tratamento complementar aplicado ao efluente de uma estação de tratamento de esgoto (ETE). Esse procedimento teve como finalidade a obtenção de água não potável para reuso direto, segundo requisitos da USEPA (2004) [4] e ABNT- NBR 13969 (1997) [5], por se tratar de uma técnica eficiente para tratar água com turbidez baixa (menor que $10 \mathrm{uH}$ ), de acordo com o recomendado por Di Bernardo e Dantas [6].

O objetivo deste trabalho foi, por meio do monitoramento do efluente da ETE, avaliar o tratamento da água por filtração rápida descendente do efluente da ETE em escala de bancada, otimizando a dosagem de coagulante e a dosagem de cloro para desinfecção e, consequentemente, obtendo água com características para reuso direto.

\section{Parte Experimental}

O estudo foi desenvolvido em ETE cujo tratamento de esgoto sanitário é realizado por processo aeróbico de lodos ativados através de dois módulos do tipo Carrossel, após tratamento preliminar e decantador primário, com capacidade máxima de operação de $25000 \mathrm{~m}^{3}$.

\subsection{Monitoramento do efluente da ETE}

Durante um período de 2 anos, foi realizado um monitoramento para verificar as características de qualidade do efluente da ETE em estudo. Dentre os parâmetros avaliados, estavam $\mathrm{pH}$ e amônia em atendimento aos padrões de lançamento em corpos d'água, alcalinidade, cor aparente, carbono orgânico total (COT), turbidez, visando à aplicação da tecnologia de filtração direta, e demanda bioquímica de oxigênio (DBO5 dias, $20^{\circ} \mathrm{C}$ ), Escherichia coli e sólidos suspensos totais (SST), parâmetros importantes à qualidade da água destinada ao reuso direto. Todos os métodos empregados foram realizados segundo APHA [7].

\subsection{Ensaios em bancada simulando FDD}

Com o foco na aplicação da filtração direta para produção de reuso, segundo as recomendações de Di Bernardo e Dantas [6], apesar de a mesma estar relacionada à água bruta de mananciais (que possui altos valores de DBO, sólidos dissolvidos e principalmente $E$. Coli e com turbidez abaixo de $10 \mathrm{uT}$ ), foram realizados ensaios em bancada em equipamento jar-test acoplado a filtros de areia de laboratório, tudo com o objetivo de obter as condições de coagulação através de um diagrama de coagulação em ensaios, simulando a filtração direta descendente em filtro de areia.

Para esses ensaios, empregaram-se colunas de acrílico preenchidas de areia, com $1 \mathrm{~cm}$ de diâmetro, denominadas de filtros de laboratório com areia (FLA), acopladas ao jar-test (Figura 1). Para execução dos ensaios de FDD, foi preparada uma areia, com leito de aproximadamente $20 \mathrm{~cm}$, por meio de classificação granulométrica com mistura para obtenção da seguinte composição: $10 \%$ em massa da areia $0,59 \mathrm{~mm}$ a 0,71 $\mathrm{mm}$ e $50 \%$ em massa de areia $0,71 \mathrm{~mm}$ a $0,84 \mathrm{~mm} ; 40 \%$ em massa de areia $0,84 \mathrm{~mm}$ a $1,0 \mathrm{~mm}$. As condições operacionais foram gradiente de mistura rápida de $1000 \mathrm{~s}^{-1}(436 \mathrm{rpm}) \mathrm{e}$ tempo de mistura rápida de 30 segundos, em seguida a rotação foi mantida em $100 \mathrm{rpm}$ com uma taxa de filtração de aproximadamente $70 \mathrm{~m}^{3} \cdot \mathrm{m}^{-2} \cdot \mathrm{d}^{-1}$. Após 15 minutos de filtração, iniciou-se a coleta de alíquotas para avaliar turbidez remanescente. Através da elaboração de diagramas com dosagem de coagulante em função do $\mathrm{pH}$ de coagulação e da turbidez remanescente, foram identificadas as regiões que apresentaram eficiência na remoção de turbidez.

Definida a melhor condição de coagulação, combinação de uma dosagem ótima de coagulante e melhor $\mathrm{pH}$ de remoção, levando em conta remoção de cor, turbidez e economia de produtos químicos, foram realizados ensaios simulando a filtração direta. Na água filtrada foram coletados aproximadamente $6 \mathrm{~L}$ a cada ensaio e os seguintes parâmetros de controle foram avaliados: $\mathrm{pH}$ de coagulação; turbidez e COT.

\subsection{Ensaios de desinfecção com oxidação química com cloro}

A desinfecção foi realizada após a simulação da tecnologia de FDD (coagulação e filtração em areia). Nesta etapa, a dosagem de cloro empregada foi determinada com base em ensaios de demanda de hipoclorito de sódio $12 \% \mathrm{p} / \mathrm{v}$. Foram aplicadas diferentes dosagens de cloro em porções de $100 \mathrm{~mL}$ de água tratada por FDD e, após um tempo de contato de 30 minutos, foi quantificado o teor de cloro residual livre, pelo método espectrofotométrico com uso de reagente de $\mathrm{N}, \mathrm{N}$ Dietil-P-Phenilenodiamina (DPD). O critério de seleção da dosagem a ser empregado na desinfecção, foi a obtenção de um teor de cloro residual livre de $1,0 \mathrm{mg} \mathrm{L}^{-1}$, valor recomendado para reuso urbano irrestrito segundo USEPA [4], observando a ocorrência da superação do cloro combinado com amônia. 


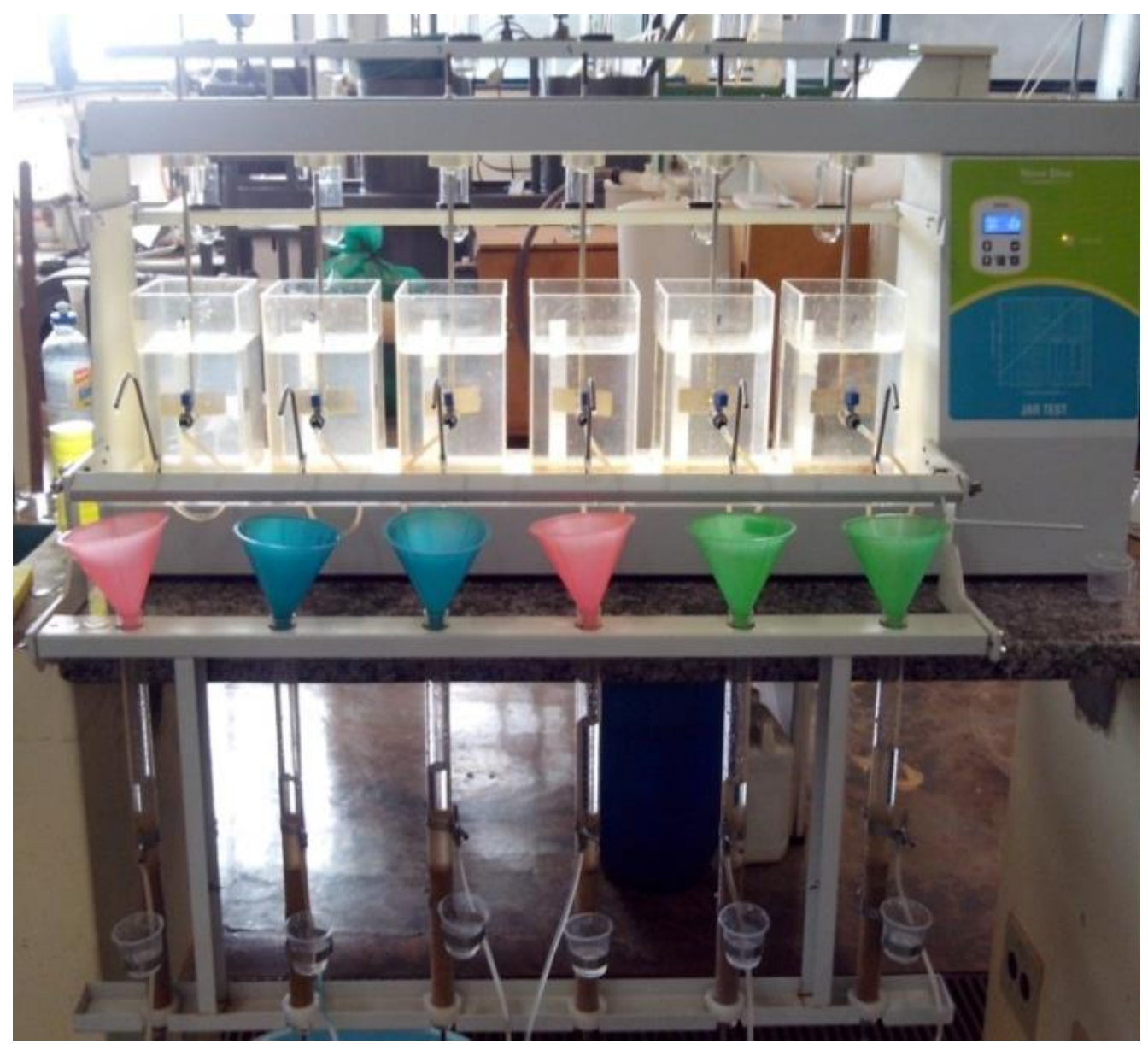

Figura 1: Jar-test acoplado aos filtros de laboratório

\section{Resultados e discussões}

\subsection{Monitoramento do efluente}

Os resultados de monitoramento do efluente da ETE foram importantes para o conhecimento da qualidade, assim como a ocorrência de suas variações; alguns parâmetros foram comparados às recomendações de qualidade requerida para reuso segundo USEPA e NBR 13969 [4,5]. O período de monitoramento situa-se entre janeiro de 2015 e janeiro de 2018. Na Tabela 1, estão apresentados os valores médios e respectivo desvio padrão obtidos no monitoramento da qualidade do Efluente da ETE.

Pelos resultados obtidos no período monitorado e pela comparação aos valores máximos recomendados para lançamento, observou-se que o efluente da ETE atende aos padrões de lançamento para os valores de $\mathrm{pH}$, nitrogênio amoniacal e DBO, podendo-se inferir que a tecnologia de tratamento biológico empregada na ETE opera com eficiência; e pelos desvios obtidos observa-se que não ocorrem variações significativas, exceto para E.coli, com valores em torno de 102 e 104, considerando que um tratamento biológico em nível secundário não objetiva a inativação de microrganismos.

Em relação aos resultados de monitoramento com vistas ao reuso, no período monitorado, a qualidade do efluente da ETE não atende aos requisitos para esse fim [4,5], no que diz respeito aos parâmetros de $\mathrm{DBO}$ e $E$. coli, o que leva à consideração da necessidade do emprego de uma tecnologia complementar ao tratamento biológico. Destacam-se os valores obtidos de COT de $81 \pm 65 \mathrm{mg} \mathrm{L}^{-1}$, que confirmam a presença residual de matéria orgânica, que é reconhecidamente precursora da formação de subprodutos halogenados $[3,8]$.

\subsection{Ensaios de FDD em bancada}

Com o foco na aplicação da tecnologia de FDD, segundo as recomendações de Di Bernardo [6], apesar de a mesma se referir à água bruta de mananciais, os resultados do monitoramento apontam para a possibilidade de aplicação da FDD no efluente da ETE. Nesse caso, considera-se principalmente que os resultados de turbidez no período 
monitorado apresentou valores de 3,9 $\pm 1,8$ uT e o valor recomendado para $90 \%$ do tempo é que seja inferior a $10 \mathrm{uT}$.

Nos resultados dos ensaios em jar-test, simulando a tecnologia de FDD com o coagulante PAC, obteve-se a dosagem otimizada de $15 \mathrm{mg} / \mathrm{L}$ de $\mathrm{PAC}$, com $\mathrm{pH}$ de coagulação de 7,35; cor aparente $20 \mathrm{uH}$ de e turbidez remanescente de 0,9 uT. Na Figura 2, é mostrado o diagrama de coagulação, obtido nos ensaios, em que varia a dosagem de coagulante e pH com adição de $\mathrm{NaOH}$, em que a turbidez remanescente em cada ensaio é representada pelo tamanho da bolha.

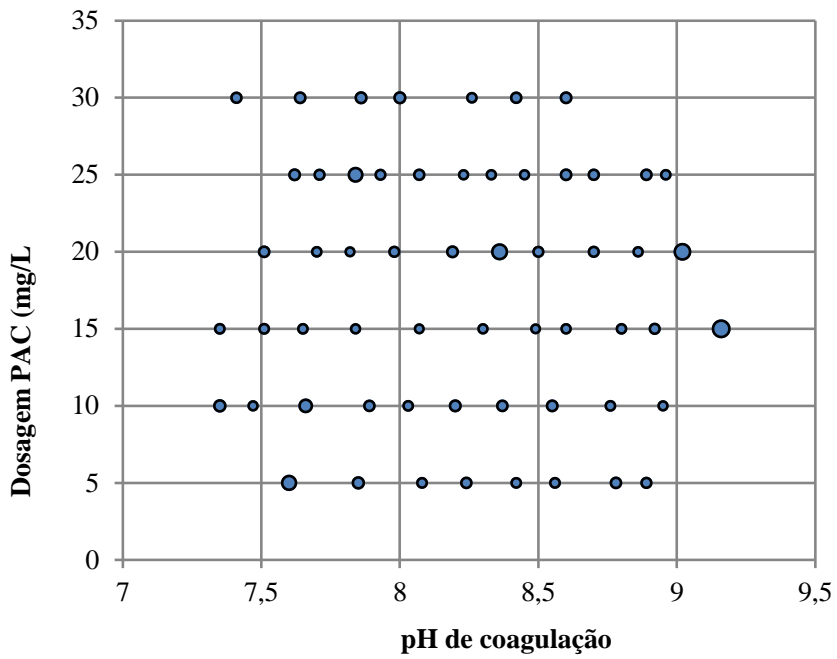

Figura 2 - Ensaios em jar-test simulando FDD para construção do diagrama de coagulação e otimização da dosagem de PAC, através da turbidez remanescente.
Os resultados obtidos na caracterização da água filtrada nos ensaios de FDD após definida a melhor condição de coagulação (15 mg $\mathrm{L}^{-1}$ de $\mathrm{PAC}$ e $\mathrm{pH}$ de 7,35), estão apresentados na Tabela 1 .

\subsection{Resultados dos ensaios de FDD com oxidação}

A partir da otimização da dosagem de PAC na etapa de coagulação, foram realizados os ensaios de FDD para geração de água de reuso, destinada aos subsequentes ensaios de desinfecção. Esta água de reuso foi então submetida a diferentes dosagens de cloro com tempo de contato de 30 minutos, objetivando a determinação da demanda de cloro para obtenção de $1 \mathrm{mg} / \mathrm{L}$ de cloro residual livre [3]. Na Figura 2 estão apresentados os resultados do ensaio de demanda de cloro da água de reuso obtendo-se na dosagem de $5,3 \mathrm{mg} \mathrm{Cl}_{2} / \mathrm{L}$ um teor de cloro residual livre em torno de $1,0 \mathrm{mg} \mathrm{Cl}_{2} / \mathrm{L}$.

Os resultados obtidos, considerando os parâmetros de referência recomendados pela USEPA e NBR nº13969 [4,5] para água de reuso, atenderam aos requisitos para produção deste tipo de água, pois foram obtidos $\mathrm{pH}$ médio de 7,8 , cor aparente $<1 \mathrm{uT}$, turbidez $<0,8 \mathrm{uT}$, cloro residual de $1 \mathrm{mg} / \mathrm{L}$, COT de $5,1 \mathrm{mg} / \mathrm{L}$, DBO de $5 \mathrm{mg} / \mathrm{L} \mathrm{O}_{2}$ e E.coli <2, como observado por Marrengula [3]. A literatura não apresenta trabalhos com aplicação de filtração direta visando a produção de água de reuso, o que ressalta a importância deste estudo em escala piloto para possível aplicação prática.

Tabela 1. Resultados expressos em valores médios e desvio padrão (DP) do monitoramento do efluente da ETE e os valores de referência.

\begin{tabular}{|c|c|c|c|c|c|}
\hline \multirow[b]{2}{*}{ Parâmetro } & \multirow[b]{2}{*}{ Unidade } & \multirow[b]{2}{*}{ Média } & \multirow[b]{2}{*}{ DP } & \multicolumn{2}{|c|}{ Valores de Referência } \\
\hline & & & & *Reúso & $* * \mathrm{FDD}$ \\
\hline $\mathrm{pH}$ & adimensional & 7,30 & 0,17 & 6,0 a 9,0 & $\mathrm{nc}$ \\
\hline Cor aparente & $\mathrm{uH}$ & 40 & 10 & nc & $<20$ \\
\hline Turbidez & uT & 3,9 & 1,8 & $<5$ & $<10$ \\
\hline Nitrogênio amoniacal & $\mathrm{mg} \mathrm{NH}_{3} \mathrm{~L}^{-1}$ & 1,73 & 1,30 & nc & $\mathrm{nc}$ \\
\hline Alcalinidade bicarbonato & $\mathrm{mg} \mathrm{CaCO}_{3} \mathrm{~L}^{-1}$ & 127 & 18 & $\mathrm{nc}$ & $\mathrm{nc}$ \\
\hline $\mathrm{DBO}_{5}$ dias a $20^{\circ} \mathrm{C}$ & $\mathrm{mg} \mathrm{O}_{2} \mathrm{~L}^{-1}$ & 10 & 6 & $<10$ & $\mathrm{nc}$ \\
\hline Carbono orgânico total & $\operatorname{mg~C~L}{ }^{-1}$ & 81 & 65 & $\mathrm{nc}$ & $\mathrm{nc}$ \\
\hline Sólidos suspensos totais & $\mathrm{Mg} \mathrm{L}^{-1}$ & 6 & 3 & $\leq 30$ & $\leq 25$ \\
\hline Escherichia Coli & $\mathrm{NMP} / 100 \mathrm{~mL}$ & 6441 & 8935 & $<200$ & $<500$ \\
\hline
\end{tabular}

* USEPA e NBR 13969 [4,5].

** Recomendações Di Bernardo [6] para 90\% do tempo. 


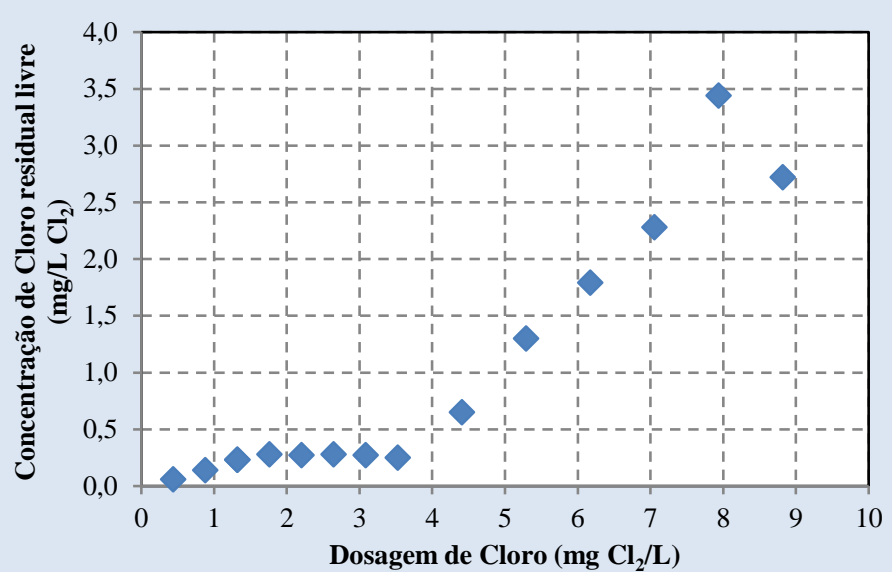

Figura 3 - Resultados do ensaio de demanda de cloro da água de reuso coagulada com PAC.

\section{Conclusões}

De acordo com os resultados obtidos neste estudo, podese concluir que a qualidade da água para fins de reuso do efluente secundário, sem ter sido submetido a qualquer tratamento, não atende aos requisitos das Diretrizes da USEPA e das Normas Técnicas [4,5], ressaltando a importância de uma tecnologia complementar para adequação de destinação ao reuso.

Pelo monitoramento, a qualidade do efluente sob a aplicação da tecnologia por FDD, não apresentou variações significativas principalmente: $\mathrm{pH}$ entre 7,30 a 8,00, Cor aparente $40 \pm 10,19 \mathrm{uH}$ e turbidez $3,9 \pm 1,30 \mathrm{uT}$, confirmando a viabilidade de estudos para o emprego da tecnologia de FDD.

A partir dos ensaios de tratamento de FDD com o coagulante PAC, concluiu-se que a dosagem otimizada é de 15 $\mathrm{mg} / \mathrm{L}$, seguida de desinfecção com cloro da dosagem de 5,3 $\mathrm{mg} / \mathrm{L} \mathrm{Cl}_{2}$ e tempo de contato de 30 minutos. Isso levou a resultados satisfatórios de turbidez com $0,8 \mathrm{uT}$, cor aparente $<1$

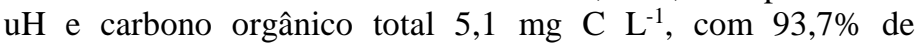
remoção e a inativação de $99,99 \%$ de E. Coli e obtendo-se um teor desejável de cloro residual livre de $0,90 \mathrm{mg} \mathrm{L}^{-1} \mathrm{Cl}_{2}$.

A tecnologia de filtração direta descendente pode ser uma opção viável com baixo custo de implantação para obtenção de água de reuso com qualidade, despontando como uma alternativa eficaz para produção de água de reuso. Recomendam-se estudos em escala piloto para definição de parâmetros hidráulicos e operacionais.

\section{DIRECT DESCENDING FILTRATION IN SANITARY SEWAGE EFFLUENT FOR PRODUCTION OF DIRECT REUSE WATER}

ABSTRACT: Water scarcity is a global problem. Thus, techniques such as reuse, which aim to fill this gap, reduce the demand on water resources, save large volumes of drinking water from improper use, and decrease the effluent load in the rivers. In this context, it was proposed the application of direct downward filtration (DDF) technology in sand, as a tertiary treatment to the secondary effluent from a sewage treatment plant (STE), in order to obtain direct reuse water. Among the main advantages of this technology are the low cost, the ease of operation and the production of water of sufficient quality for the application of less noble purposes. For this purpose, the Effluent (ETE) of a city in the interior of the state of São Paulo was monitored, in order to evaluate the water quality and ensure the adequacy of the application of DDF as a technological resource. Treatment trials were carried out in jar-test using aluminum polychloride coagulant (APC), followed by oxidation with chlorine. The result of the ETE effluent monitoring showed low turbidity values, with little variation during the study period, presenting adequate quality for DDF application. The optimum dosage for the coagulant APC was $15 \mathrm{mg} \mathrm{L}^{-1}$. The DDF assays followed by chlorine oxidation provided reuse water with apparent color of 20 $\mathrm{uH}$; turbidity of $0.8 \mathrm{uT}$; $\mathrm{pH}$ of about 7.5 and free chlorine residual of $1 \mathrm{mg} \mathrm{L}^{-1}$. These results meet the quality recommendations established by USEPA (2004) and NBR 13969 (ABNT, 1997). It can be concluded that the water quality obtained by applying DDF technology, followed by chlorine oxidation, meets the demand for unrestricted urban reuse for less noble water use applications such as irrigation of gardens, washing of floors and spaces and storage for firefighting.

Keywords: Water reuse. Direct Descending Filtration. Sewage effluent. Disinfection.

\section{Referências}

[1] MANCUSO, P. C. S.; SANTOS, H.F.; Reuso de Água. NISAM - US Barueri, São Paulo, Manole, 2003.

[2] CETESB. Reuso da água. São Paulo. SP. Disponível em: <http://www.cetesb.sp.gov.br/agua rios/gesta_reuso.asp> Acesso em: 02/05/2018.

[3] Marrengula, Fernando Afonso. Avaliação da filtração direta descendente no tratamento de efluente de estação de tratamento de esgoto para reuso não potável. Dissertação de Mestrado apresentado a Universidade de Ribeirão Preto - 2016.

[4] United State Environmental Protection Agency (USEPA). Guidelines for Water Reuse. EPA/600/R-12/618. Office of Water, Washington, DC, 2004.

[5] Associação Brasileira de Normas Técnicas (ABNT), Normas Brasileiras Regulamentadoras (NBR) no 13969. Projeto, Construção e Operação de Unidades de Tratamento Complementar e Disposição Final dos Efluentes de Tanques Sépticos: procedimentos. Rio de Janeiro, 57p, 1997.

[6] DI BERNARDO, L.; DANTAS, A.D.B.; VOLTAN, P.E.N.; Métodos e técnicas de tratamento de água, $3^{\mathrm{a}} \mathrm{ed}, 2017$.

[7] AMERICAN PUBLIC HEALTH ASSOCIATION (APHA); AMERICAN WATER WORKS ASSOCIATION (AWWA); WATER ENVIRONMENT FEDERATION (WEF). Standard Methods for the Examination of water and Wastewater. 20th edition. Washington, EUA, 2005.

[8] SINGER, P. C; ASCE, M. Controle de subprodutos de desinfecção na água potável. JEE-ASCE, v. 120, n. 4 p.727-741. Julho / Agosto, EUA. (1994). 